\title{
Elemental abundance analyses with Complejo Astronomico El Leoncito REOSC echelle spectrograms
}

\section{HR 4487, 14 Hydrae, and 3 Centauri A}

\author{
O.I. Pintado ${ }^{1, \star, \star \star}$, S.J. Adelman ${ }^{2, \star \star \star}$, and A.F. Gulliver ${ }^{3}$ \\ 1 Complejo Astronómico El Leoncito, CC 468, 5400 San Juan, Argentina \\ 2 Departament of Physics, The Citadel, 171 Moultrie Street, Charleston, SC 29409, U.S.A. \\ e-mail: adelmans@citadel.edu \\ 3 Department of Physics and Astronomy, Brandon University, Brandon, MB R7A 6A9, Canada
}

Received April 2; accepted October 30, 1997

\begin{abstract}
Using CASLEO echelle spectrograms, elemental abundances are derived for the sharp-lined nonmagnetic CP stars HR 4487, 14 Hya, and 3 Cen A. The first two stars are members of the Mercury-Manganese subgroup and have abundances which are similar to other such peculiar stars. The third is a hotter related star. The detection of Mn II lines in its spectrum adds to this relationship ${ }^{1}$.
\end{abstract}

Key words: stars: abundances - stars: chemically peculiar - stars: individual: HR 4487, 14 Hya, 3 Cen A

\section{Introduction}

This paper presents elemental abundance analyzes of three sharp-lined B stars using spectrograms obtained with the 2.15-m telescope of the Complejo Astronomico El Leoncito (CASLEO) and a REOSC echelle spectrograph, which is on loan from the Institute Astrophysique de Liège,

Send offprint requests to: S.J. Adelman

* Member of Carrera del Investigador del Consejo Nacional de Investigaciones Científicas y Técnicas de la República Argentina.

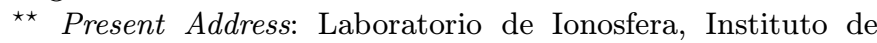
Fisica, Facultad de Ciencias Exactas y Tecnología, Universidad Nacional de Tucumán, Av. Independencia 1800. 4000 San Miguel de Tucumán Argentina.

${ }^{\star \star \star}$ Visiting Astronomer at Complejo Astronómico El Leoncito Operated under agreement between Consejo Nacional de Investigaciones Científicas y Técnicas de la República Argentina and the National Universities of La Plata, Córdoba and San Juan.

1 Table 3 is avaible electronically vit the CDS via anonymous ftp 130.79.128.5 or http://cdsweb.u-strasbg.fr/Abstract.html
Belgium, and a TEK 1024 CCD. The cross disperser was a grating with 1200 lines $\mathrm{mm}^{-1}$. (See Paper I, Pintado \& Adelman 1996, for additional details.)

Table 1. The derived $\mathrm{He} / \mathrm{H}$ ratios

\begin{tabular}{lccc}
\hline Wavelength $(\AA)$ & HR 4487 & 14 Hya & 3 Cen A \\
\hline 3867 & $\ldots$ & $\ldots$ & 0.02 \\
4009 & $\ldots$ & $\ldots$ & 0.03 \\
4026 & $\ldots$ & $\ldots$ & 0.02 \\
4121 & $\ldots$ & $\ldots$ & 0.02 \\
4169 & $\ldots$ & $\ldots$ & 0.03 \\
4388 & 0.04 & $\ldots$ & 0.03 \\
4472 & 0.02 & 0.04 & 0.03 \\
4713 & $\ldots$ & 0.05 & 0.02 \\
4922 & 0.02 & $\ldots$ & $\ldots$ \\
\hline Average & 0.03 & 0.04 & 0.02 \\
\hline
\end{tabular}

Paper II (Adelman \& Pintado 1997) found that the equivalent width scale of these spectrograms for lines whose equivalent widths are $15 \mathrm{~m} \AA$ or greater is marginally greater than those for Kitt Peak National Observatory (KPNO) coudé feed CCD and Dominion Astrophysical Observatory (DAO) Reticon spectrograms. Further the $\lambda \lambda 4500-5600$ region for Mercury-Manganese $(\mathrm{HgMn})$ stars contains many unblended lines which are useful for increasing the quality of abundance studies based on KPNO and DAO spectrograms. This region contains a sufficient number of lines for high quality abundance analyses. In this paper we study two HgMn stars and one hotter somewhat similar star.

The bright Southern star HR 4487 (= HD 101189) is a member of NGC 3766 which is part of the Sco-Cen 
Table 2. Determination of the microturbulences

\begin{tabular}{llllllll}
\hline Star & Species & $\begin{array}{l}g f \\
\text { values }\end{array}$ & $n$ & $\begin{array}{l}\xi_{1} \\
(\mathrm{~km} / \mathrm{s})\end{array}$ & $\log \mathrm{Fe} / N_{\mathrm{T}}$ & $\begin{array}{l}\xi_{2} \\
(\mathrm{~km} / \mathrm{s})\end{array}$ & $\log \mathrm{Fe} / N_{\mathrm{T}}$ \\
\hline $14 \mathrm{Hya}$ & Fe II & $\mathrm{MF}+\mathrm{KX}$ & 30 & 0.3 & $-4.70 \pm 0.33$ & 0.3 & $-4.70 \pm 0.33$ \\
& adopted & & & 0.3 & & & \\
$3 \mathrm{C}$ Cen A & Fe II & $\mathrm{MF}+\mathrm{KX}$ & 64 & 1.1 & $-4.47 \pm 0.30$ & 1.1 & $-4.47 \pm 0.30$ \\
& adopted & & & 1.1 & & & \\
\hline
\end{tabular}

$g f$ value references: $\mathrm{KX}=$ Kurucz (1995), MF $=$ Fuhr et al. (1988).

Association. Heck et al. (1987) suspected it is a long period photometric variable. Bidelman (1988) comments it is a remarkable Ap star that deserves detailed study.

Stickland \& Weatherby (1984) found $v \sin i=$ $35 \mathrm{~km} \mathrm{~s}^{-1}$ for the HgMn Star 14 Hya (= HR $3500=$ HD 75333). Adelman \& Pyper (1979) obtained optical spectrophotometry.

Jugaku et al. (1961) performed an abundance analysis of 3 Cen A (= HR $5210=$ HD 120709) which is a hot nonmagnetic CP star, probably related to the $\mathrm{HgMn}$ stars. Sargent \& Jugaku (1961) determined that $84 \%$ of its $\mathrm{He}$ is $\mathrm{He}^{3}$. Latter Sargent et al. (1969) found it has a normal $\mathrm{Ne}$ abundance, weak He I lines, and normal $\mathrm{C}$ II lines. It is not a member of the Scorpio-Centaurus OB Association (Thompson et al. 1987). De Geus et al. (1989) found $T_{\text {eff }}=18200 \mathrm{~K}, \log g=4.18$ from Walraven photometry. Breger (1976) includes optical spectrophotometry in the Hayes-Latham (1975) system. Recently Castelli et al. (1997) derived the abundances using high dispersion IUE exposures.

\section{Effective temperatures and surface gravities}

For HR 4487, we used the homogeneous uvby $\beta$ colors of Hauck \& Mermilliod (1980) with the calibration of Napiwotzki et al. (1993) and found $T_{\text {eff }}=11020 \mathrm{~K}, \log$ $g=3.92$. As we do not have spectrophotometry nor a Balmer line profile for this star, we adopted these values for our analysis. This method also gives $T_{\text {eff }}=12250 \mathrm{~K}$, $\log g=3.72$ for $14 \mathrm{Hya}$ and $T_{\text {eff }}=16984 \mathrm{~K}, \log g=4.40$ for 3 Cen A. For 14 Hya, comparison of spectrophotometry (Adelman \& Pyper 1979) with the predicted fluxes of an ATLAS9 solar composition model with the above combination of effective temperature and surface gravity is not optimal. Better agreement is obtained with the predictions of a $T_{\text {eff }}=12000 \mathrm{~K}, \log g=3.75$ model with no microturbulence which we adopted. For 3 Cen A, Castelli et al. (1997) derived $T_{\text {eff }}=17500, \log g=3.8$ after considering the problems with a variety of photometric data produced by contamination by the secondary which is a B star 1.5 magnitudes fainter, but only $7.9^{\prime \prime}$ away.
Table 4. Comparison of abundances $[\mathrm{N} / \mathrm{H}]$ for 3 Cen A

\begin{tabular}{lrr}
\hline Species & Castelli et al. & This Paper. \\
\hline $\mathrm{He}$ & -0.55 & -0.66 \\
$\mathrm{C}$ & -0.75 & -1.01 \\
$\mathrm{~N}$ & -0.50 & -0.16 \\
$\mathrm{O}$ & 0.00 & -0.90 \\
$\mathrm{Mg}$ & -0.50 & -0.77 \\
$\mathrm{Si}$ & -0.20 & $-0.32:$ \\
$\mathrm{P}$ & 1.60 & 1.59 \\
$\mathrm{Ar}$ & 0.00 & $0.08:$ \\
$\mathrm{Ca}$ & -1.00 & -0.74 \\
$\mathrm{Cr}$ & 0.00 & 0.51 \\
$\mathrm{Mn}$ & 1.40 & 1.50 \\
$\mathrm{Fe}$ & 0.20 & 0.28 \\
$\mathrm{Ni}$ & 0.00 & 0.16 \\
$\mathrm{Ga}$ & 3.25 & 3.55 \\
& & \\
\hline
\end{tabular}

\section{Reduction of spectrograms}

The stellar lines were identified with the general references A Multiplet Table of Astrophysical Interest (Moore 1945) and Wavelengths and Transition Probabilities for Atoms and Atomic Ions, Part 1 (Reader \& Corliss 1980) as well as the more specialized references P II (Svendenius et al. 1983), P III (Magnusson \& Zetterberg 1987), Mn II (Iglesias \& Velasco 1964), Fe II (Johansson 1978), and Ga II (Isberg \& Litzen 1985).

For HR 4487, we used CASLEO spectrograms covering $\lambda \lambda 4121-30$ and $\lambda \lambda 4170-5614$. We identified lines of $\mathrm{H}$ I, He I, C I, C II, O I, Mg I, Mg II, Si II, S II, Ca I, Sc II, Ti II, Cr II, Mn II, Fe I, Fe II, Ni I, Ni II, Sr II, Y II, Zr II, Ba II, Hg I, and possibly Mn I. For 14 Hya we analyed $\lambda \lambda 4434-5076$. In this region we found lines of H I, He I, Mg II, Si II, P II, Ti II, Cr II, Mn I, Mn II, Fe II, and Y II.

For 3 Cen A we compared our equivalent width values with those by Jugaku et al. (1961) who used photographic plates taken with the coudé spectrograph of the 5-m 
Table 5. Comparison of Hot HgMn Star Abundances (log N/H)

\begin{tabular}{|c|c|c|c|c|c|c|c|c|}
\hline Species & $\begin{array}{l}3 \\
\text { Cen A }\end{array}$ & $\begin{array}{l}33 \\
\text { Gem }\end{array}$ & $\begin{array}{l}\mathrm{HR} \\
7361\end{array}$ & $\kappa \mathrm{Cnc}$ & $\begin{array}{l}\text { HR } \\
8349\end{array}$ & $\begin{array}{l}\mathrm{HR} \\
7664\end{array}$ & $\pi^{1}$ Boo & Sun \\
\hline He I & -1.70 & -1.96 & -2.00 & -2.26 & -1.72 & -2.10 & -1.72 & -1.04 \\
\hline C II & -4.44 & -3.82 & -3.89 & -3.97 & -3.54 & -3.88 & -3.81 & -3.43 \\
\hline N II & -4.11 & $\ldots$ & $\ldots$ & $\ldots$ & $\ldots$ & $\ldots$ & $\ldots$ & -3.95 \\
\hline O I & $\ldots$ & $\ldots$ & -3.23 & $\ldots$ & $\ldots$ & $\ldots$ & -3.43 & -3.14 \\
\hline O II & -4.04 & -3.23 & -2.82 & $\ldots$ & -2.59 & $\ldots$ & -2.76 & -3.14 \\
\hline $\mathrm{Mg} \mathrm{I}$ & $\ldots$ & $\ldots$ & $\ldots$ & -5.17 & -5.27 & $\ldots$ & -5.20 & -4.42 \\
\hline Mg II & -5.19 & -4.81 & -5.14 & -5.17 & -4.94 & -5.75 & -4.79 & -4.42 \\
\hline $\mathrm{Al} \mathrm{I}$ & $\ldots$ & $\ldots$ & $\ldots$ & $\ldots$ & -6.29 & $\ldots$ & $\ldots$ & -5.53 \\
\hline Si II & $-4.66:$ & $\ldots$ & -4.19 & -4.48 & -4.16 & -4.48 & -4.31 & -4.45 \\
\hline Si III & -4.88 & -4.76 & -4.56 & -4.47 & -4.26 & -4.80 & -4.47 & -4.45 \\
\hline P II & -4.84 & -4.54 & -4.52 & -4.73 & -4.65 & -4.99 & -5.66 & -6.55 \\
\hline P III & -5.09 & $\ldots$ & -4.45 & -4.77 & -4.88 & $\ldots$ & $\ldots$ & -6.55 \\
\hline S II & $\ldots$ & $\ldots$ & -5.66 & -5.56 & -5.08 & -5.48 & -5.24 & -4.67 \\
\hline Ar II & -5.36 & $\ldots$ & $\ldots$ & $\ldots$ & $\ldots$ & $\ldots$ & $\ldots$ & $-5.44:$ \\
\hline $\mathrm{Ca}$ II & -6.38 & $\ldots$ & -4.93 & -5.67 & -4.95 & -5.55 & -5.17 & -5.64 \\
\hline Sc II & $\ldots$ & -7.45 & -7.94 & -8.37 & -7.67 & -9.14 & -7.64 & -8.90 \\
\hline Ti II & $\ldots$ & -5.82 & -6.83 & -6.82 & -6.86 & -6.20 & -6.75 & -7.01 \\
\hline V II & $\ldots$ & $\ldots$ & $\ldots$ & -7.60 & $\ldots$ & $\ldots$ & $\ldots$ & -8.00 \\
\hline Cr II & -5.75 & -5.89 & -6.15 & -6.42 & -6.11 & -6.70 & -5.69 & -6.26 \\
\hline Mn I & $\ldots$ & $\ldots$ & -3.97 & -4.39 & -4.28 & $\ldots$ & -4.07 & -6.45 \\
\hline Mn II & -4.95 & -4.21 & -4.10 & -4.45 & -4.16 & -5.42 & -4.18 & -6.45 \\
\hline $\mathrm{Fe} \mathrm{I}$ & $\ldots$ & -3.80 & -4.23 & -4.49 & -4.65 & -3.96 & -4.84 & -4.52 \\
\hline Fe II & -4.26 & -3.90 & -4.41 & -4.57 & -4.46 & -4.44 & -4.08 & -4.52 \\
\hline Fe III & -4.22 & -4.31 & -4.26 & -4.44 & -4.22 & -4.04 & -4.64 & -4.52 \\
\hline $\mathrm{Ni}$ II & -5.59 & $\ldots$ & -6.21 & -6.18 & -6.11 & -6.15 & -6.77 & -5.75 \\
\hline Ga II & -5.57 & -6.63 & -4.81 & -4.75 & $\ldots$ & -6.14 & -4.86 & -9.12 \\
\hline Sr II & $\ldots$ & $\ldots$ & $-8.46:$ & -8.54 & -7.88 & -8.75 & -6.84 & -9.10 \\
\hline Y II & $\ldots$ & $\ldots$ & -7.59 & -8.33 & -7.17 & -8.21 & -6.36 & -9.76 \\
\hline Zr II & $\ldots$ & $\ldots$ & $\ldots$ & $\ldots$ & -7.33 & $\ldots$ & $\ldots$ & -9.40 \\
\hline Xe II & $\ldots$ & -5.55 & -5.22 & -5.60 & $\ldots$ & $\ldots$ & $\ldots$ & $(-9.77)$ \\
\hline Ba II & $\ldots$ & $\ldots$ & $\ldots$ & $\ldots$ & $\ldots$ & $\ldots$ & $\ldots$ & -9.87 \\
\hline $\mathrm{Hg} \mathrm{I}$ & $\ldots$ & $\ldots$ & $\ldots$ & $\ldots$ & $\ldots$ & $\ldots$ & $\ldots$ & $(-10.91)$ \\
\hline$\underline{\mathrm{Hg}} \mathrm{II}$ & $\ldots$ & $\ldots$ & -6.00 & -5.98 & -5.67 & -7.40 & -5.27 & $(-10.91)$ \\
\hline$\overline{T_{\text {eff }}}$ & 17500 & 14375 & 13300 & 13125 & 12975 & 12875 & 12700 & \\
\hline $\log g$ & 3.80 & 3.90 & 3.75 & 3.59 & 3.90 & 3.51 & 4.02 & \\
\hline
\end{tabular}

telescope at Palomar. For 52 metal lines we found with the equivalent widths in $\mathrm{m} \AA$,

$$
W_{\lambda}(\mathrm{CASLEO})=0.7871 W_{\lambda}(\text { Palomar })+2.78
$$

which is fair agreement. As to atomic species they identified lines of H I, He I, C II, N II, O I, O II, Ne I, Mg II, Si II, Si III, P II, P III, S II, Ar II, Ca II, Fe II, Fe III, Ni II, Ga II, and Kr II. We did not confirm those of O I, Ne I, and S II, but this is more a choice of spectral region and found in addition lines of Cr II and Mn II. Our spectrograms covered $\lambda \lambda 3849-3868, \lambda \lambda 3906-3936$, $\lambda \lambda 3991-4685, \lambda \lambda 4712-4860$, and $\lambda \lambda 5010-5508$ with a few minor gaps between orders.

\section{The elemental abundance analyses}

We employed programs SYNSPEC (Hubeny et al. 1994) and WIDTH9 (Kurucz, private communication), respec- tively, to determine the helium and metal abundances. The adopted metal-line damping constants were the default semi-classical approximations, except for iron-peak element lines, whose values were based on the data of Kurucz (1995). We applied a 3\% scattered light correction to account for light scattered along the direction of the dispersion, which is an appropriate value for clean optical systems (Gulliver et al. 1996).

Table 1 contains the derived $\mathrm{He} / \mathrm{H}$ ratios from lines on the CASLEO spectrograms. For all three stars, these values are much less than solar and similar to those for many HgMn stars.

Table 2 summarizes the determination of the microturbulence using Fe II lines. Those for $\xi_{1}$ were found by demanding that the derived abundances be independent of equivalent width and those of $\xi_{2}$ by minimizing the standard deviation of the mean. No entries are given for HR 4487 as the Fe II lines indicated that the values might 
Table 6. Comparison of Cool HgMn star abundances $(\log \mathrm{N} / \mathrm{H})$

\begin{tabular}{|c|c|c|c|c|c|c|c|c|c|c|c|c|}
\hline Species & $\pi^{1}$ Boo & $\mu$ Lep & 14 Hya & $53 \mathrm{Tau}$ & $v$ Her & $\phi$ Her & HR 4487 & HR $4072 \mathrm{~A}$ & $28 \mathrm{Her}$ & HR 7775 & $\nu \mathrm{Cnc}$ & Sun. \\
\hline He I & -1.72 & -1.57 & -1.40 & -1.80 & -1.82 & -1.62 & -1.53 & -1.46 & -2.00 & -1.60 & -1.57 & $(-1.01)$ \\
\hline C I & $\ldots$ & $\ldots$ & $\ldots$ & $\ldots$ & $\ldots$ & $\ldots$ & -3.47 & -3.37 & $\ldots$ & $\ldots$ & $\ldots$ & -3.34 \\
\hline C II & -3.81 & -3.68 & $\ldots$ & -3.95 & -4.07 & -3.58 & -3.13 & -3.23 & -3.94 & -4.10 & -3.88 & -3.34 \\
\hline O I & -3.43 & $\ldots$ & $\ldots$ & $\ldots$ & $\ldots$ & $\ldots$ & -3.24 & $\ldots$ & -3.37 & -3.58 & $\ldots$ & -3.07 \\
\hline O II & -2.76 & $\ldots$ & $\ldots$ & $\ldots$ & $\ldots$ & $\ldots$ & $\ldots$ & $\ldots$ & $\ldots$ & $\ldots$ & $\ldots$ & -3.07 \\
\hline $\mathrm{Mg} \mathrm{I}$ & -5.20 & -5.17 & $\ldots$ & $\ldots$ & -5.56 & -5.28 & -4.77 & -4.65 & -5.51 & -4.74 & -4.66 & -4.42 \\
\hline $\mathrm{Mg}$ II & -4.79 & -4.76 & -4.77 & -4.94 & -5.08 & -4.80 & -4.98 & -4.57 & -5.26 & -4.67 & -4.71 & -4.42 \\
\hline $\mathrm{Al} \mathrm{I}$ & $\ldots$ & $\ldots$ & $\ldots$ & $\ldots$ & $\ldots$ & $\ldots$ & $\ldots$ & -6.42 & $\ldots$ & -6.69 & -6.38 & -5.53 \\
\hline Al II & $\ldots$ & $\ldots$ & $\ldots$ & $\ldots$ & $\ldots$ & $\ldots$ & $\ldots$ & -6.85 & $\ldots$ & $\ldots$ & & -5.53 \\
\hline Si I & $\ldots$ & $\ldots$ & $\ldots$ & $\ldots$ & $\ldots$ & $\ldots$ & $\ldots$ & $\ldots$ & $\ldots$ & $\ldots$ & -4.78 & -4.45 \\
\hline $\mathrm{Si} \mathrm{II}$ & -4.31 & -4.29 & $\ldots$ & -4.65 & -4.82 & -4.64 & -4.30 & -4.53 & -4.78 & -4.50 & -4.50 & -4.45 \\
\hline Si III & -4.47 & -4.22 & $\ldots$ & -4.59 & -4.85 & $\ldots$ & $\ldots$ & $\ldots$ & & $\ldots$ & $\ldots$ & -4.45 \\
\hline P II & -5.66 & -5.41 & -6.07 & $\ldots$ & -5.82 & $\ldots$ & $\ldots$ & -5.54 & -5.60 & -5.59 & $\ldots$ & -6.55 \\
\hline P III & $\ldots$ & $\ldots$ & $\ldots$ & $\ldots$ & $\ldots$ & $\ldots$ & $\ldots$ & $\ldots$ & $\ldots$ & $\ldots$ & $\ldots$ & -6.55 \\
\hline S II & -5.24 & -4.68 & -4.72 & -5.34 & -5.29 & -4.91 & -3.94 & -4.64 & -4.35 & -4.72 & -5.05 & -4.79 \\
\hline $\mathrm{Ca} \mathrm{I}$ & $\ldots$ & & $\ldots$ & -5.34 & $\ldots$ & -5.20 & -5.67 & -5.24 & -6.11 & -5.24 & -6.21 & -5.64 \\
\hline Ca II & -5.17 & -5.27 & $\ldots$ & -5.02 & -5.83 & -5.36 & $\ldots$ & -4.80 & -5.51 & -5.25 & -6.06 & -5.64 \\
\hline Sc II & -7.64 & -8.43 & $\ldots$ & -9.54 & -9.06 & -7.47 & -8.13 & -8.40 & $\ldots$ & -9.55 & -8.19 & -8.90 \\
\hline Ti II & -6.75 & -6.41 & -5.69 & -5.76 & -6.26 & -6.37 & -6.76 & -6.16 & -6.82 & -6.08 & -6.38 & -7.01 \\
\hline V II & $\ldots$ & $\leq-7.44$ & $\ldots$ & & $\ldots$ & $\ldots$ & $\ldots$ & -8.68 & $\ldots$ & -8.18 & -8.20 & -8.00 \\
\hline Cr I & $\ldots$ & & $\ldots$ & -5.80 & $\ldots$ & -5.18 & $\ldots$ & -5.69 & -5.90 & -5.75 & -5.73 & -6.33 \\
\hline Cr II & -5.69 & -5.89 & -5.53 & -5.89 & -6.12 & -5.50 & -5.35 & -5.62 & -6.16 & -5.72 & -5.88 & -6.33 \\
\hline Mn I & -4.07 & -4.58 & -4.46 & -4.45 & -4.70 & -4.92 & $-4.35:$ & -5.51 & -5.62 & -5.83 & -6.21 & -6.61 \\
\hline Mn II & -4.18 & -4.45 & -4.68 & -4.56 & -4.88 & -5.08 & -5.13 & -5.38 & -5.48 & -5.84 & -5.84 & -6.61 \\
\hline $\mathrm{Fe} I$ & -4.84 & -4.77 & $\ldots$ & -5.28 & -4.76 & -4.35 & -4.10 & -4.00 & -4.37 & -4.12 & -4.44 & -4.52 \\
\hline $\mathrm{Fe}$ II & -4.88 & -4.62 & -4.67 & -5.24 & -4.85 & -4.59 & -4.39 & -4.08 & -4.35 & -4.22 & -4.60 & -4.52 \\
\hline Fe III & -4.64 & -4.67 & $\ldots$ & -4.65 & -4.68 & -4.64 & $\ldots$ & -3.97 & -4.32 & -4.08 & $\ldots$ & -4.52 \\
\hline $\mathrm{Ni} \mathrm{I}$ & $\ldots$ & $\ldots$ & $\ldots$ & $\ldots$ & $\ldots$ & $\ldots$ & $\ldots$ & $\ldots$ & $\ldots$ & $\ldots$ & -5.58 & -5.75 \\
\hline $\mathrm{Ni}$ II & -6.77 & -6.32 & $\ldots$ & -6.49 & -6.77 & -6.26 & -5.07 & -6.62 & $\ldots$ & -6.60 & -5.62 & -5.75 \\
\hline Ga II & -4.86 & $-4.44:$ & $\ldots$ & -6.41 & -5.64 & -6.00 & $\ldots$ & $\ldots$ & $\ldots$ & -5.34 & $\ldots$ & -9.12 \\
\hline Sr II & -6.84 & -7.32 & $\ldots$ & -8.17 & -8.10 & -8.34 & -6.74 & -6.49 & -6.62 & -6.48 & -8.01 & -9.10 \\
\hline Y II & -6.36 & -7.14 & -7.08 & -8.20 & -7.76 & -6.72 & -7.02 & -6.56 & -6.67 & -6.94 & -7.76 & -9.76 \\
\hline Zr II & $\ldots$ & $\leq-8.34$ & $\ldots$ & -7.49 & -8.95 & -7.32 & -6.76 & -8.04 & -8.53 & -8.73 & -7.60 & -9.40 \\
\hline $\mathrm{Ba}$ II & $\ldots$ & $\ldots$ & $\ldots$ & $\leq-9.55$ & -8.85 & $\leq-8.06$ & $\ldots$ & -9.14 & $\leq-9.81$ & -9.70 & $\leq-6.97$ & -9.87 \\
\hline La II & $\ldots$ & $\ldots$ & $\ldots$ & $\ldots$ & $\ldots$ & $\ldots$ & $\ldots$ & -9.29 & $\ldots$ & $\ldots$ & $\ldots$ & -10.78 \\
\hline Pr II & $\ldots$ & $\ldots$ & $\ldots$ & $\ldots$ & $\ldots$ & $\ldots$ & $\ldots$ & $\ldots$ & $\ldots$ & -7.72 & $\ldots$ & -11.29 \\
\hline $\mathrm{Nd}$ II & $\ldots$ & $\ldots$ & $\ldots$ & $\ldots$ & $\ldots$ & $\ldots$ & $\ldots$ & $\ldots$ & $\ldots$ & -7.82 & $\ldots$ & -10.50 \\
\hline Gd II & $\ldots$ & $\ldots$ & $\ldots$ & $\ldots$ & $\ldots$ & $\ldots$ & $\ldots$ & $\ldots$ & $\ldots$ & -9.15 & -9.29 & -10.88 \\
\hline Ho II & $\ldots$ & $\ldots$ & $\ldots$ & $\ldots$ & $\ldots$ & $\ldots$ & $\ldots$ & $\ldots$ & $\ldots$ & -8.90 & $\ldots$ & -11.7 \\
\hline Tm II & $\ldots$ & $\ldots$ & $\ldots$ & $\ldots$ & $\ldots$ & $\ldots$ & $\ldots$ & $\ldots$ & $\ldots$ & -9.47 & $\ldots$ & -12.00 \\
\hline Pt I & $\ldots$ & $\ldots$ & $\ldots$ & $\ldots$ & $\ldots$ & $\ldots$ & $\ldots$ & $\ldots$ & $\ldots$ & $-5.53:$ & $\ldots$ & -10.2 \\
\hline Pt II & $\ldots$ & $\ldots$ & $\ldots$ & $\ldots$ & $\ldots$ & $\ldots$ & $\ldots$ & -7.32 : & $-7.68:$ & $-7.23:$ & $\ldots$ & -10.2 \\
\hline $\mathrm{Au} \mathrm{II}$ & $\ldots$ & $\ldots$ & $\ldots$ & $\ldots$ & $\ldots$ & $\ldots$ & $\ldots$ & $-7.34:$ & $\ldots$ & $-7.18:$ & $\ldots$ & -10.99 \\
\hline $\mathrm{Hg} \mathrm{I}$ & $\ldots$ & -5.75 & $\ldots$ & $\ldots$ & -6.02 & -6.33 & $\ldots$ & -5.67 & $\ldots$ & -5.90 & $\ldots$ & $(-10.91)$ \\
\hline $\mathrm{Hg}$ II & -5.27 & -5.65 & $\ldots$ & $\ldots$ & -5.76 & -6.38 & $\ldots$ & -5.83 & -7.80 & -6.06 & -7.80 & $(-10.91)$ \\
\hline$T_{\text {eff }}$ & 12700 & 12400 & 12000 & 12000 & 11900 & 11325 & 11020 & 10900 & 10900 & 10650 & 10650 & . \\
\hline $\log g$ & 4.02 & 3.91 & 3.75 & 4.21 & 3.74 & 3.79 & 3.92 & 4.07 & 3.96 & 4.13 & 4.13 & . \\
\hline
\end{tabular}

be larger than a few $\mathrm{km} \mathrm{s}^{-1}$, which is inconsistent with values found for other HgMn stars. The problem is that we have not observed a sufficient number of Fe II lines which are beyond the linear part of the curve-of-growth. Thus we adopt the most common value of $0.0 \mathrm{~km} \mathrm{~s}^{-1}$ for this class of star.

Table $3^{2}$ contains the metal line results from our spectra. For each line, they contain the multiplet number, the wavelength in $\AA$, the equivalent width in $\mathrm{m} \AA$, the gf value and its source, and the derived abundance $(\log N / N(\mathrm{~T}))$ where $N(\mathrm{~T})$ is the total number of atoms per unit volume.

2 Table 3 is available only in electronic form at the CDS via anonymous ftp to 130.79 .128 .5 .

\section{Discussion}

For HR 4487, the Mg I and Mg II abundances are in acceptable agreement while the difference between the Fe I and Fe II abundances is 0.3 dex. The Mn I and Mn II abundances are in still worse agreement. But the two Mn I lines are weak and thus we believe the result from the Mn II lines. The disagreement between Fe I and Fe II line results suggest that the effective temperature and surface gravity might need a slight adjustment, but we do not have the data to do this. For 14 Hya the Mn I and Mn II lines give similar results. While for 3 Cen A the Si II multiplet 3 lines better agree with the abundance derived from Si III lines than do the Si II multiplet 1 lines which yield larger results. The P II and P III line abundances are in fair agreement while the Fe II and Fe III lines show excellent agreement. 
Our results for 3 Cen A compared with those for Jugaku et al. (1969) reflect changes in the gf values over the past 25 years. In Table 4 we compare our results with those of Castelli et al. (1997). For most of the derived elements in common, the agreement is at least acceptable ( 0.4 dex or better). Our analysis finds $\mathrm{O}$ is about $1 \mathrm{dex}$ underabundant while Castelli et al. find a solar value. But the visible region analysis of Hardorp et al. (1968) agrees with our value. Also we find $\mathrm{Cr}+0.5$ dex overabundant compared with their solar value.

In Table 5 we compare our results with those of some of the hotter HgMn stars and the Sun. Although many of its abundances are similar to those of the hottest $\mathrm{HgMn}$ stars, 3 Cen $\mathrm{A}$ is $2500 \mathrm{~K}$ hotter than any of these which makes a comparison difficult. It is $\mathrm{C}, \mathrm{O}, \mathrm{Mg}$ and $\mathrm{Ca}$ underabundant, Si, Fe, and Ni normal, N, A, and Cr overabundant, and $\mathrm{P}, \mathrm{Mn}$, and Ga very overabundant. In making these comparisons, the error in $\mathrm{He} / \mathrm{H}$ is about 0.01 while in those of other elements is typically $0.3 \mathrm{dex}$.

Considering the errors in the abundances, most of those derived for HR 4487 are within the range of values seen at its effective temperature in other HgMn stars (Table 6, Adelman et al. 1996; Adelman \& Pintado 1997). It is apparently one of the most Si rich members, a result which needs to be confirmed. It may be the most $\mathrm{S}, \mathrm{Cr}$, $\mathrm{Ni}$, and $\mathrm{Zr}$ rich $\mathrm{HgMn}$ star studied with modern analyses.

Compared with other HgMn stars 14 Hya has a relatively mild He underabundance. Its other abundanc generally fall within the range of values seen at its effective temperature except that it is slightly less $\mathrm{P}$ rich. Obtaining additional abundances of this star and the other two analyzed in this paper would be desirable.

Acknowledgements. OIP is grateful to the staff of CASLEO for their assistance during the observing runs. The authors acknowledge the use of the CCD and data reduction acquisition system supported by US NSF Grant AST 90-15827 to R.M. Rich. SJA thanks The Citadel Development Foundation for several grants which supported in part this collaboration.

\section{References}

Adelman S.J., Pintado O.I., 1997, A\&AS 125, 219

Adelman S.J., Philip A.G.D., Adelman C.J., 1996, MNRAS 282,953

Adelman S.J., Pyper D.M., 1979, AJ 84, 1603

Bidelman W.P., 1988, PASP 100, 1084

Biemont E., Grevesse N., Hannaford P., Lowe R.M., 1981, ApJ 248,867

Castelli F., Parthasarathy M., HacK M., 1997, A\&A 321, 254

De Geus E.J., de Zeeuw P.T., Lub J., 1989, A\&A 216, 44

Fuhr J.R., Martin G.A., Wiese W.L., 1988, J. Phys. Chem. Ref. Data 15, Suppl. 4
Fuhr J.R., Wiese W.L., 1990, in Lide D.R., (ed.) CRC Handbook of Chemistry and Physics, CRC Press. Cleveland, $\mathrm{OH}$

Grevesse N., Biemont E., Hannaford P., Lowe R.M., 1981, Upper Main Sequence Stars, 23rd Liege Astrophys. Coll., p. 211

Gulliver A.F., Hill G., Adelman S.J., 1996, in Model Atmospheres and Spectrum Synthesis, Adelman S.J., Kupka F., Weiss W.W. (eds.) ASP, San Francisco, ASP Conf. Ser. 108, 232

Hannaford P., Lowe R.M., Grevesse N., Biemont E., 1982, ApJ 261,736

Hardorp J., Bidelman W.P., Prölss J., 1966, Zsf. für Astrophys. 69,429

Hayes D.S., Latham D.W., 1975, ApJ 197, 593

Heck A., Mathys G., Manfroid J., 1987, A\&AS 70, 33

Hubeny I., Lanz T., Jeffery C.S., 1994, Daresbury Lab. New. Anal. Astron. Spectra No. 20, p. 30

Iglesias L., Velasco R., 1964, Publ. Inst. Opt. Madrid No. 23

Isberg B., Litzen U., 1985, Phys. Scr. 31, 533

Johansson S., 1978, Phys. Scr. 18, 217

Jugaku J., Sargent W.L.W., Greenstein J.L., 1961, ApJ 134, 783

Kurucz R.L., 1995, in Astrophysical Applications of Powerful New Databases, Adelman S.J., Wiese W.L. (eds.) ASP, San Francisco, ASP Conf. Ser. 78, 205

Lanz T., Artru M.-C., 1985, Phys. Scr. 32, 155

Lanz T., Dimitrijevic M.S., Artru M.-C., 1988, A\&A 192, 249

Lawler J.E., Dakin J.T., 1989, JOSA B 6, 1457

Magnusson C.E., Zetterberg P.O., 1977, Phys. Scr. 15, 237

Martin G.A., Fuhr J.R., Wiese W.L., 1988, J. Phys. Chem. Ref. Data 15, Suppl. 3

Moore C.E., 1945, A Multiple Table of Astrophysical Interest. Princeton University Observatory, Princeton

Napiwotzki R., Schonberner D., Wenske V., 1993, A\&A 268, 653

Pintado O.I., Adelman S.J., 1996, A\&AS 118, 283

Reader J., Corliss C.H., 1980, NSRDS-NBS 68, Part 1, US Government Printing Office, Washington, DC

Sargent A.I., Greenstein J.L., Sargent W.L.W., 1969, ApJ 157, 757

Sargent W.L.W., Jugaku J., 1961, ApJ 134, 777

Sahal-Brechot S., 1969, A\&A 2, 322

Stickland D.J., Weatherby J., 1984, A\&AS 57, 55

Svendenius N., Magnusson C.E., Zetterberg P.O., 1983, Phys. Scr. 27, 339

Thompson I.B., Brown D.N., Landstreet J.D., 1987, ApJS 64, 219

Wiese W.F., Fuhr J.R., Deters T.M., 1996, J. Phys. Chem. Ref. Data Monograph 6

Wiese W.L., Martin G.A., 1980, NSRDS-NBS 68. Part 2, US Government Printing Office, Washington, DC

Wiese W.L., Smith M.W., Glennon B.M., 1966, NSRDS-NBS 4, US Government Printing, Office, Washington, DC

Wiese W.L., Smith M.W., Miles B.M., 1969, NSRDS-NBS 22, US Government Printing Office, Washington, DC 